\title{
Determination of the Microbiological Quality of Feed City Water to Pharmaceutical Facility: Distribution Study and Statistical Analysis
}

\author{
By Mostafa Essam Eissa *
}

Supplying feeding water to pharmaceutical plant is critical both for industrial or human consumption purposes. Assessment of microbiological quality and stability is needed to determine the suitability of income city water for human application and other processing in pharmaceutical manufacturing. In the current study statistical analysis and Shewhart charts were used to determine the degree of compliance of the raw city water to the standard microbiological specifications. Although all sampling points of the distribution system met the acceptance criteria, they showed variable degrees of out-of-control states at chronologically non-identical parts of the control charts. The performance of each monitored compartment could be measured by a bioburden level which might provide indication for the disinfection efficacy. The overall capability of the process (Ppk) for each segment of the distribution system was found in the following descending order: water station (2.30), restaurant (2.25), laboratory locker (2.08) and production locker (1.86). Despite the presence of residual chlorine level, the distribution system showed variable degrees of biological instability. Thus, disinfection of feed water cannot be used as a sole measure for protection of aged distribution network and further investigation is required to improve the system quality and maintenance in demand of delivering microbiologically high quality and safe water.

Keywords: Chlorine, City water, Out-of-control, Pharmaceutical plant, Shewhart charts.

\section{Introduction}

The objective of the open drinking water system network is to create water of acceptable tangible and hygienic properties and to keep up that quality all the way through transfer network till the location of use. From a microbiological point of view, the desired properties of the produced water can decay as an after effect of extensive bacterial proliferation. This microbial growth can prompt issues, for example, a marked impairment of water quality (e.g. taste, scent, turbidity, staining) and additionally objectionable microbes multiplication (Bartram et al., 2004; Boe-Hansen et al., 2002; Hammes et al., 2008; Juhna et al., 2007; Vital et al., 2010; Vital et al., 2008, Pharmaguideline.com, 2016).

Drinking water (potable) is classified under Type II class of water that is required to satisfy the necessities of the Environmental Protection Agency (EPA) for quality. It originates from a particular supply or city source that has

${ }^{*}$ Head, Microbiology Section, HIKMA Pharma, Egypt. 
different levels of hardness and included chlorine for microbial control as described by Vincent, 2003. Drinking water ought to be supplied under constant positive pressure in a pipes framework free of any anomalies that could prompt tainting of infrastructures of the system with consequent deterioration of water quality. Drinking water is unchanged with the exception of constrained treatment of the water supplied from a natural or storage area. Examples of normal sources of water comprise springs, wells, streams, lakes, ocean and sea. The state of the source water will manage the treatment required to render it within acceptable and safe standard limits for human utilization (drinking). Processing of water includes desalinization, removal of hardness, removing certain ions, reduction of particulate matter and disinfection (WHO, 2003).

Water for human consumption is acquired mainly from a local water network yet might likewise be drawn from wells, waterways, or lakes. Pipes system network deformities might bring about the pollution of clean feeding water. As a result of this probability, inspection of the use points by sampling is crucial to monitor water quality. Drawing the sample in such case will be representative for water that flows through the distribution framework. In addition, Microbial pollution of oral fluid and topical medication items keeps on being a critical issue, and is generally originated from the utilization of contaminated water. In spite of the fact that there are no supreme microbial measures for water (other than water proposed to be sterile), the cGMP regulations require that suitable criteria should be built up and observed. The criteria must consider the dedicated utilization of the water (FDA, 2016).

Another study in the same line has shown the influence of the microbial quality of raw water on the final purified water of the pharmaceutical facility that is produced from the water treatment station loop for medicinal products manufacturing. The investigation conducted by Eissa, 2016 demonstrated that the income water microbiological count may affect the final product water quality although there are barriers for the passage of microbial cells during processing stages of drinking water.

Due to the previously mentioned challenges, the current study aimed to perform long term inspection on the microbiological quality of feeding potable water to a pharmaceutical facility for manufacturing of non-sterile medicinal products. The work focused on providing a simple system for monitoring and evaluating the microbiological stability of supply city water. The supply in turn is used for general human consumption purposes and preparation of purified water for pharmaceutical uses specifically. The study covered three different terminal supply lines from the main old (aged) water station that feeds the firm with city water using process control charts and statistical analysis.

\section{Materials and Methods}

Principally, the present study was performed using standard methods in water sampling and testing using a conventional culture technique. The output data generated from the microbiology laboratory were then trended and 
subjected to a statistical analysis using commercial statistical software package. After processing the results, not only the microbiological efficiency of the distribution system could be evaluated, but also its state of biological stability could be assessed. Accordingly, any corrective, maintenance and/or improvement plans, after that, should be investigated based on the outcome of the analysis. Microbiological samples of city water small framework system feeding pharmaceutical plant for non-sterile medicinal products - were sampled over 38 months excluding shutdowns, weekends and maintenance periods. The study was conducted in the industrial zone at $6^{\text {th }}$ of October city, Egypt. The diagram of the city water distribution system is shown in Figure 1. The small plant for city water is aged over 25 years with its associated network pipes that supply the manufacturing plant with chlorinated feed water. An old water station comprises a $300 \mathrm{~m}^{3}$ tank that pumped water to the distribution system that supplies the restaurant, production locker and laboratory locker. Environmental monitoring (EM) samples - during testing under laminar air flow (LAF) unit, water sampling and testing were done according to Ashour et al. 2011. All microbiological culture media for microbial processing and chemicals were purchased from OXOID (Basingstoke, Hampshire) and SigmaAlrich (St. Louis, MO 63103), respectively. Plastic $9 \mathrm{~mm}$ sterile plates were bought from Sterilin Limited (solaar house, 19 mercers row, Cambridge, UK). Enumeration of colonies after incubation was conducted with the aid of digital colony counter (Digital Colony Counter Model: 361, Laxman Mahtre Rd. Navagaon, Dahisar West, Mumbai). All culture media were sterilized by autoclaving in a steam sterilizer (FEDEGARI FOB3, Fedegari Autoclavi SpA, SS $235 \mathrm{~km} \mathrm{8,} 27010$ Albuzzano (PV), Italy). All pH measurements and weighing of media and reagents were performed using Mettler-Toledo S20 SevenEasy ${ }^{\mathrm{TM}} \mathrm{pH}$ Meter and XPE Analytical Balance, respectively (MettlerToledo, LLC 1900 Polaris Parkway Columbus, OH 43240). Incubation of media plates and tubes was done in BD 115 incubator (BINDER GmbH, ImMittlerenÖsch 5 D-78532 Tuttlingen) and Hotpack incubator (incubator 175 series, model 417532, Hotpack, Dutton Rd., Philadelphia, USA). For microscopic examination, a microscope with oil immersion lens (ACCUSCOPE \#A3000, Mel Sobel Microscopes Ltd., USA) was used. Timer (HX175B, Shenzhen Heng Teng Fa Electronics Co., Ltd., Shenzhen/Guangdong, China) was used during monitoring and testing to control time. Microbiological culture media used in the current study were all subjected to the growth promotion test as described in the compendial guideline (Clontz, 2008). Negative control plates were prepared and incubated in parallel with the test plates to ensure sterility of the culture media and aseptic processing monitoring. The identification of the suspect waterborne isolates for coliforms and/or Pseudomonas aeruginosa was conducted using diminutive biochemical identifications kits BBL ${ }^{\mathrm{TM}}$ Crystal $^{\mathrm{TM}}$ enteric/non fermenter (E/NF) and Grampositive (GP) Identification System Identification System and Gram stain reagents purchased from BD (Becton Dickinson Microbiology Systems, Cockeysville, Md.). The identification procedure was done as detailed in the manual of the kit. All microbiological processing and handling were made 
under validated and calibrated biological safety cabinet (Jouan MSC 9 Class II A2 BioSafety Cabinet, Thermo Fisher Scientific Inc. 81 Wyman Street, Waltham, MA, USA 02451). The microbiological limit of the city water was set as recommended by the Environmental Protection Agency (EPA) (Bartram, 2004). Application of statistical process control (SPC) and Six Sigma tools were done as described by Eissa et al., 2015. Illustrations of generated data, testing data distribution and compound calculations were performed using Microsoft Office Excel 2007. GraphPad Prism v6.01 for windows was used for complex statistical analysis in addition to correlation studies, control charts and Pareto diagram were constructed using Minitab ${ }^{\circledR}$ v17.1.0.

Figure 1. Diagram showing Distribution System of City Water (in Simplified Form) that Feeds Pharmaceutical Plant for Non-sterile Manufacturing in the Industrial Zone (Dashed Line Indicates that the Compartment is at the Next Level Above the Other Parts of the Distribution System)

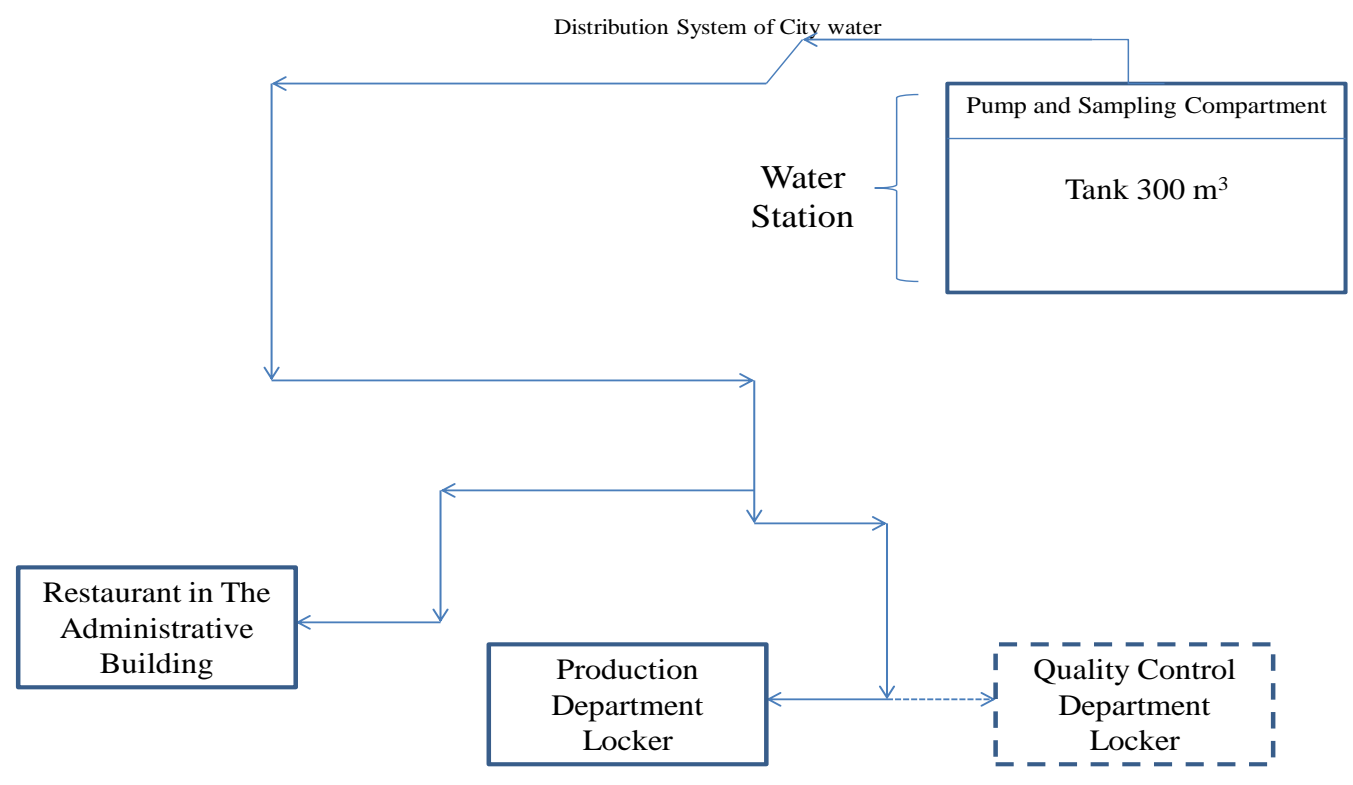

\section{Results and Discussion}

During the period of the study, there were no unusual signs in color, odor, or turbidity in water samples across sampling sites. All microbiological results of the samples showed absence of coliforms and $P$. aeruginosa. The examination of the microbial count distribution over a 38 months period on a monthly basis showed that it did not follow normal distribution as shown in Figure 2. On the other hand, Figure 3 demonstrates the trends of microbial count of the four points of city water over the testing period of 38 months. While there was a tendency of increasing the microbial count in an old water station with time, the other points showed a decreasing tendency in bioburden. 
This finding requires further investigation to elucidate the reason for this difference in the trend of microbial count through the same distribution water system. The original data profile did not fit any type of discrete distribution. However, they were closest to geometric-type of distribution (Englehardt et al., 2009).

Figure 2. Histogram of Raw Data (Without Transformation) Showing the NonGaussian Microbial Count Distribution in City Water from Four Sampling Locations in the Pharmaceutical Plant

Histogram of Old Water St; Restaurant; Production L; Laboratory L

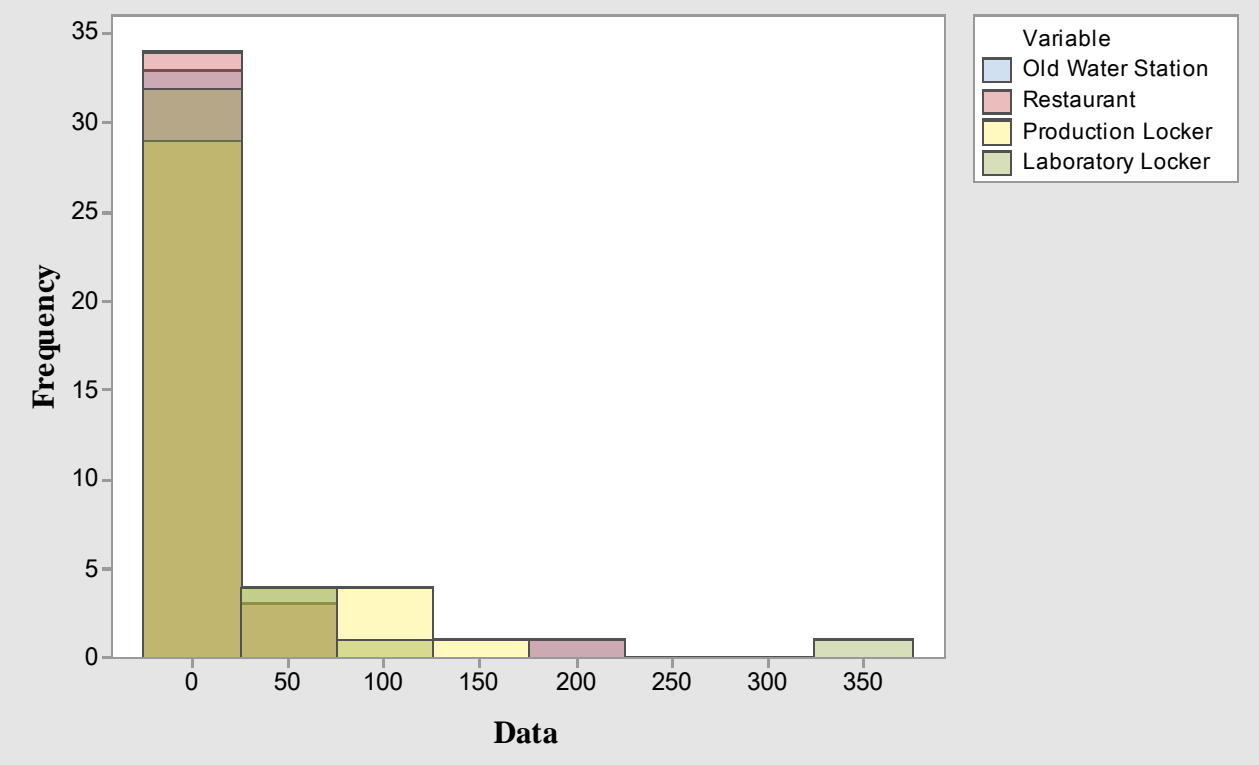

Figure 3. Bioburden Trend in City Water from Four Points of Analysis through 38 Months Period of Monitoring Excluding the Shutdown Periods

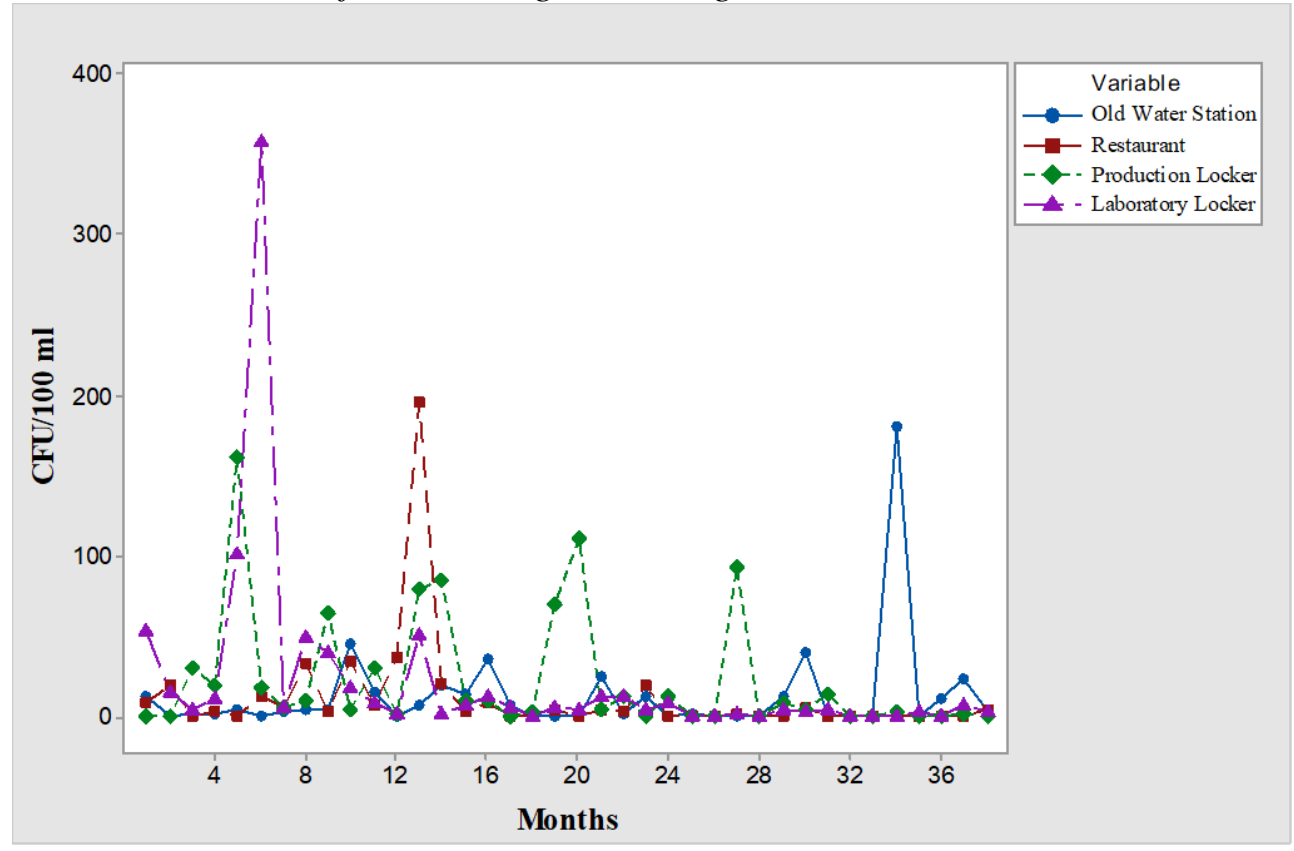


Statistical analysis of the raw untransformed data is demonstrated in Table 1. All microbiological results of the four sampling points did not show tendency to the normal distribution pattern. While all points had the same minimum value of zero, the median values of the lockers were higher than that of restaurant and old water station. The pattern of data and its descriptive outcome indicated distorted accumulation of the distribution towards the lowest microbial counts. Interestingly, Table 2 shows the effect of logarithmic transformation on the data distribution and its effect on improving normalization and approaching a Gaussian distribution pattern. It should be noted that the mean of all points was significantly higher than zero CFU/100 $\mathrm{ml}$ but old water station and restaurant mean values were significantly lower than nine CFU/100 $\mathrm{ml}$ at $\alpha=0.05$. Table 3 summarizes One-Way ANOVA test results showing that the means of the microbiological counts of the four points were not significantly different at $\alpha=0.05$. Box and plot diagram in Figure 3 demonstrates the pattern of microbial distribution for each point before and after $\log _{10}(\mathrm{CFU}+1)$ transformation with notably elimination of most outliers except one from the laboratory locker.

Table 1. Descriptive Statistics, Confidence Intervals (CI), Normality Test and Inferences of Untransformed Microbiological Data

\begin{tabular}{|c|c|c|c|c|}
\hline Column Statistics & $\begin{array}{l}\text { Old Water } \\
\text { Station }\end{array}$ & Restaurant & $\begin{array}{l}\text { Production } \\
\text { Locker }\end{array}$ & $\begin{array}{l}\text { Laboratory } \\
\text { Locker }\end{array}$ \\
\hline Minimum & 0.0 & 0.0 & 0.0 & 0.0 \\
\hline $25 \%$ Percentile & 1.0 & 0.0 & 1.0 & 2.0 \\
\hline Median & 3.0 & 3.0 & 5.5 & 5.5 \\
\hline $75 \%$ Percentile & 13 & 8.0 & 23 & 12 \\
\hline Maximum & 180 & 196 & 162 & 358 \\
\hline $10 \%$ Percentile & 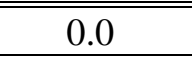 & 0.0 & 蕰 & 蕰 \\
\hline $90 \%$ Percentile & 36 & 33 & 86 & 51 \\
\hline Mean & 13 & 11 & 23 & 22 \\
\hline Std. Deviation & 30 & 32 & 38 & 60 \\
\hline Std. Error of Mean & 4.9 & 5.3 & 6.2 & 9.7 \\
\hline Lower $95 \%$ CI of mean & 3.1 & 0.83 & 11 & 2.1 \\
\hline Upper $95 \%$ CI of mean & 23 & 22 & 35 & 41 \\
\hline Lower 95\% CI of median & 1.0 & 0.0 & 2.0 & 3.0 \\
\hline Upper $95 \%$ CI of median & 11 & 6.0 & 12 & 9.0 \\
\hline \multicolumn{5}{|l|}{$\begin{array}{l}\text { D'Agostino \& Pearson } \\
\text { omnibus normality test }\end{array}$} \\
\hline $\mathrm{K} 2$ & 74 & 79 & 28 & 77 \\
\hline $\mathrm{P}$ value & $<0.0001$ & $<0.0001$ & $<0.0001$ & $<0.0001$ \\
\hline $\begin{array}{l}\text { Passed normality test }(\alpha= \\
0.05) ?\end{array}$ & No & No & No & No \\
\hline $\mathrm{P}$ value summary & $* * * *$ & $* * * *$ & $* * * *$ & $* * * *$ \\
\hline Skewness & 4.9 & 5.3 & 2.1 & 5.2 \\
\hline Kurtosis & 27 & 30 & 4.3 & 29 \\
\hline Sum & 493 & 436 & 875 & 824 \\
\hline
\end{tabular}


Table 2. Descriptive Statistics, Confidence Intervals (CI), Normality Test and Inferences of Logarithmically Transformed Microbiological Results

\begin{tabular}{|c|c|c|c|c|}
\hline Column Statistics & $\begin{array}{l}\text { Old Water } \\
\text { Station }\end{array}$ & Restaurant & $\begin{array}{l}\text { Production } \\
\text { Locker }\end{array}$ & $\begin{array}{l}\text { Laboratory } \\
\text { Locker }\end{array}$ \\
\hline Minimum & 0.0 & 0.0 & 0.0 & 0.0 \\
\hline $25 \%$ Percentile & 0.30 & 0.0 & 0.30 & 0.48 \\
\hline Median & 0.60 & 0.60 & 0.81 & 0.81 \\
\hline $75 \%$ Percentile & 1.2 & 0.95 & 1.4 & 1.1 \\
\hline Maximum & 2.3 & 2.3 & 2.2 & 2.6 \\
\hline $10 \%$ Percentile & 0.0 & 0.0 & 0.0 & 0.0 \\
\hline $90 \%$ Percentile & 1.6 & 1.5 & 1.9 & 1.7 \\
\hline Mean & 0.72 & 0.57 & 0.88 & 0.83 \\
\hline Std. Deviation & 0.58 & 0.61 & 0.68 & 0.62 \\
\hline Std. Error of Mean & 0.093 & 0.099 & 0.11 & 0.10 \\
\hline Lower $95 \%$ CI of mean & 0.53 & 0.37 & 0.66 & 0.63 \\
\hline Upper $95 \%$ CI of mean & 0.91 & 0.78 & 1.1 & 1.0 \\
\hline Lower $95 \%$ CI of median & 0.30 & 0.0 & 0.48 & 0.60 \\
\hline Upper $95 \%$ CI of median & 1.1 & 0.85 & 1.1 & 1.0 \\
\hline \multicolumn{5}{|l|}{\begin{tabular}{|l} 
D'Agostino \& Pearson \\
omnibus normality test
\end{tabular}} \\
\hline $\mathrm{K} 2$ & 2.5 & 4.4 & 4.8 & 2.9 \\
\hline $\mathrm{P}$ value & 0.2824 & 0.1117 & 0.0900 & 0.2309 \\
\hline $\begin{array}{l}\text { Passed normality test } \\
\text { (alpha=0.05)? }\end{array}$ & Yes & Yes & Yes & Yes \\
\hline P value summary* & ns & $\mathrm{ns}$ & $\mathrm{ns}$ & ns \\
\hline \multicolumn{5}{|l|}{ One sample $t$ test } \\
\hline Theoretical mean & 0.0 & 0.0 & 0.0 & 0.0 \\
\hline Actual mean & 0.72 & 0.57 & 0.88 & 0.83 \\
\hline Discrepancy & -0.72 & -0.57 & -0.88 & -0.83 \\
\hline $95 \%$ CI of discrepancy & 0.53 to 0.91 & 0.37 to 0.78 & 0.66 to 1.1 & 0.63 to 1.0 \\
\hline $\mathrm{t}, \mathrm{df}$ & $\mathrm{t}=7.7 \mathrm{df}=37$ & $\mathrm{t}=5.8 \mathrm{df}=37$ & $\mathrm{t}=8.0 \mathrm{df}=37$ & $\mathrm{t}=8.3 \mathrm{df}=37$ \\
\hline P value (two tailed) & $<0.0001$ & $<0.0001$ & $<0.0001$ & $<0.0001$ \\
\hline Significant $(\alpha=0.05)$ ? & Yes & Yes & Yes & Yes \\
\hline Skewness & 0.60 & 0.81 & 0.34 & 0.58 \\
\hline Kurtosis & -0.25 & 0.029 & -1.0 & 0.41 \\
\hline Sum & 27 & 22 & 34 & 32 \\
\hline
\end{tabular}

ns = Not Significant 
Table 3. One-Way ANOVA Test using Tukey's Multiple Comparisons Test Performed on Microbiological Results from Four Sampling Points of City Water Distribution System

\begin{tabular}{|c|c|c|c|c|}
\hline Number of families & 1 & & & \\
\hline $\begin{array}{l}\text { Number of comparisons per } \\
\text { family }\end{array}$ & 6 & & & \\
\hline$\alpha$ & 0.05 & & & \\
\hline Tukey's multiple comparisons test & $\begin{array}{l}\text { Mean } \\
\text { Diff. }\end{array}$ & $\begin{array}{l}95 \% \text { CI of } \\
\text { diff. }\end{array}$ & $\begin{array}{c}\text { Significance of mean } \\
\text { difference }\end{array}$ & $\begin{array}{c}\text { Summar } \\
y^{*}\end{array}$ \\
\hline Old Water Station vs. Restaurant & 0.14 & -0.23 to 0.51 & No & ns \\
\hline $\begin{array}{l}\text { Old Water Station vs. Production } \\
\text { Locker }\end{array}$ & -0.17 & -0.54 to 0.21 & No & ns \\
\hline $\begin{array}{l}\text { Old Water Station vs. Laboratory } \\
\text { Locker }\end{array}$ & -0.11 & -0.49 to 0.26 & No & ns \\
\hline Restaurant vs. Production Locker & -0.31 & $\begin{array}{c}-0.68 \text { to } \\
0.064\end{array}$ & No & ns \\
\hline Restaurant vs. Laboratory Locker & -0.26 & -0.63 to 0.12 & No & ns \\
\hline $\begin{array}{l}\text { Production Locker vs. Laboratory } \\
\text { Locker }\end{array}$ & 0.052 & -0.32 to 0.42 & No & ns \\
\hline Test details & SE of diff. & $\mathrm{q}$ & DF & \\
\hline Old Water Station vs. Restaurant & 0.14 & 1.4 & 148 & \\
\hline $\begin{array}{l}\text { Old Water Station vs. Production } \\
\text { Locker }\end{array}$ & 0.14 & 1.6 & 148 & \\
\hline $\begin{array}{l}\text { Old Water Station vs. Laboratory } \\
\text { Locker }\end{array}$ & 0.14 & 1.1 & 148 & \\
\hline Restaurant vs. Production Locker & 0.14 & 3.0 & 148 & \\
\hline Restaurant vs. Laboratory Locker & 0.14 & 2.5 & 148 & \\
\hline $\begin{array}{l}\text { Production Locker vs. Laboratory } \\
\text { Locker }\end{array}$ & 0.14 & 0.51 & 148 & \\
\hline
\end{tabular}

ns $=$ Not Significant

Pearson correlation at $95 \%$ confidence interval (CI) and two-tailed $\mathrm{P}$ showed significant relation between the distributions of data for the four points. This finding was demonstrated clearly in Table 4.

Table 4. Pearson Correlation (r) Matrix between Every Pair of Data Set for the Water Sampling Points at $95 \%$ Confidence Interval (CI) $(*=$ Significant Correlation)

\begin{tabular}{|c|c|c|c|c|}
\hline \multirow{2}{*}{$\begin{array}{c}\text { Pearson Correlation Matrix of City } \\
\text { Water Samples }\end{array}$} & \multicolumn{4}{|c|}{ Correlation (r) (P values) } \\
\cline { 2 - 5 } & $\begin{array}{c}\text { Old Water } \\
\text { Station }\end{array}$ & Restaurant & $\begin{array}{c}\text { Production } \\
\text { Locker }\end{array}$ & $\begin{array}{c}\text { Laboratory } \\
\text { Locker }\end{array}$ \\
\hline \multirow{2}{*}{ Old Water Station } & & $0.252^{*}$ & 0.014 & 0.118 \\
& & $(0.127)$ & $(0.933)$ & $(0.479)$ \\
\hline \multirow{2}{*}{ Restaurant } & $0.252^{*}$ & & 0.205 & $0.508^{*}$ \\
& $(0.127)$ & & $(0.217)$ & $(0.001)$ \\
\hline \multirow{2}{*}{ Production Locker } & 0.014 & 0.205 & & $0.480^{*}$ \\
& $(0.933)$ & $(0.217)$ & & $(0.002)$ \\
\hline \multirow{2}{*}{ Laboratory Locker } & 0.118 & $0.508^{*}$ & $0.480^{*}$ & \\
& $(0.479)$ & $(0.001)$ & $(0.002)$ & \\
\hline
\end{tabular}


Shewhart control charts for each sampling point of the pharmaceutical distribution system for the city water were illustrated using Individual-moving Range (I-MR) charts as shown in Figures 5-8. Special-cause variations were present at least once during the testing period - with the exception of the production locker - which could be attributed to external factors not related to the normal process. Nevertheless, the overall capability of the process $\left(\mathrm{P}_{\mathrm{pk}}\right)$ for each segment of the distribution system was found in the following descending order: old water station (2.30), restaurant (2.25), laboratory locker (2.08) and production locker (1.86) which exceeded the benchmark value of 1.33 (Support.Minitab.com, 2016). Strangely, persistent but fluctuating levels of chlorine were observed at points-of-use by an online monitoring system. The decrease in the efficacy with distance could be attributed partially to what was observed by some researchers. While Chlorination of potable water is an effective treatment for microbial removal as demonstrated by FDA 2016, this antimicrobial interacts not only with bacteria, but it also get consumed by natural organic substances, piping surface material and particulate matters in the distribution network, which in turn leads to the production of assimilable organic carbon (AOC) (LeChevallier et al., 1996; Polanska et al., 2005; Ramseier et al., 2011; Van der Kooij, 1990; Weinrich et al., 2010). AOC can readily be used by bacteria, and hence can be viewed as a major source for what is called "biological instability". In addition, the decomposition of chlorine in the distribution system adversely impacts its antimicrobial properties at the far ends of the network (Niquette et al., 2001). The average performance of the feed water distribution system is shown in Figure 9. The average $\mathrm{P}_{\mathrm{pk}}$ was 2.33 with one point in the last section of the MR chart unusually unstable process variation due to freak or extraneous factor(s). However, the upper control limit (UCL) of the water station, restaurant, production and the laboratory lockers was approximately 216, 94, 548 and 163 CFU/100 ml, respectively. Since CL provides a measure of dispersion in control charts for specific inspected quality characteristic (Berardinelli, 2016), it was applied for comparison between different segments of distributing the system of city water. By using UCL as a measure for microbiological quality, the Pareto chart was constructed as shown in Figure 10 to demonstrate the segment of the system with the highest risk of microbial count fluctuation. In such condition, this approach may be an advantage over measuring defects as part per million (PPM) because the later could not reveal any significant difference as the three points showed 0.00 PPM and the production locker 0.01 PPM. Transformation improved normalization of the distribution by minimizing over dispersion as shown in Figure 4. 
Figure 4. Box Whisker Plot Showing Bioburden Distribution Pattern and Outliers (Demonstrated by Asterisks) of Untransformed (Upper Graph) and Transformed (Lower Graph)

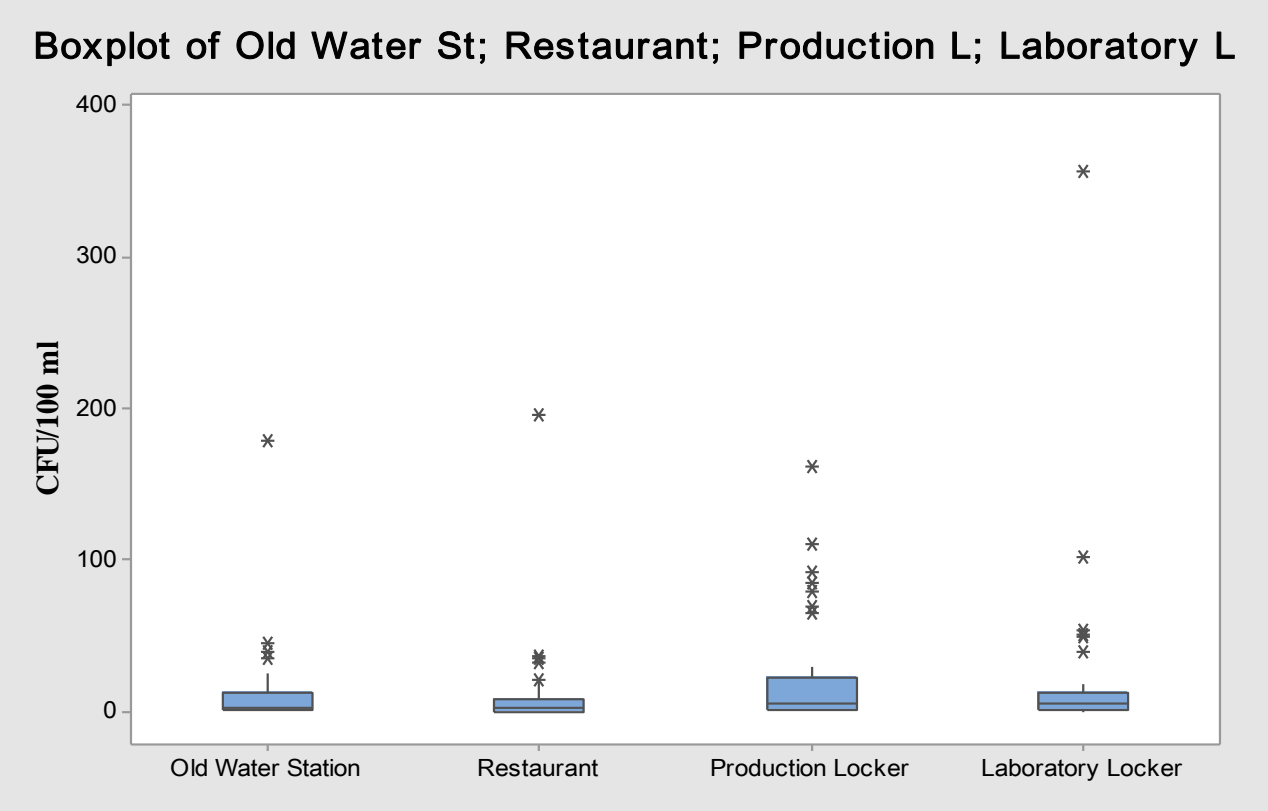

Boxplot of Old Water St; Restaurant; Production L; Laboratory L

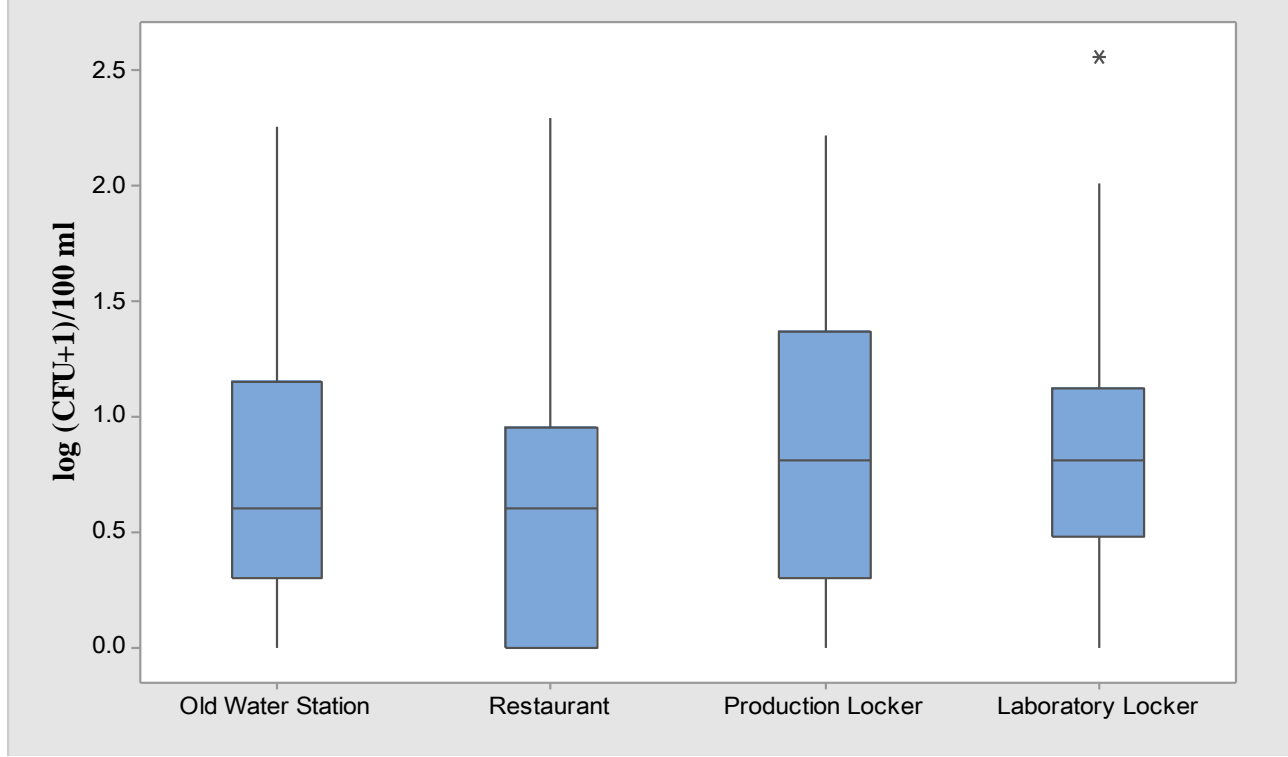


Figure 5. Shewhart Chart of the Pharmaceutical City Water Station Sampling Port Covering a Period of 38 Months of Microbiological Sampling and Testing I-MR Chart of Old Water Station
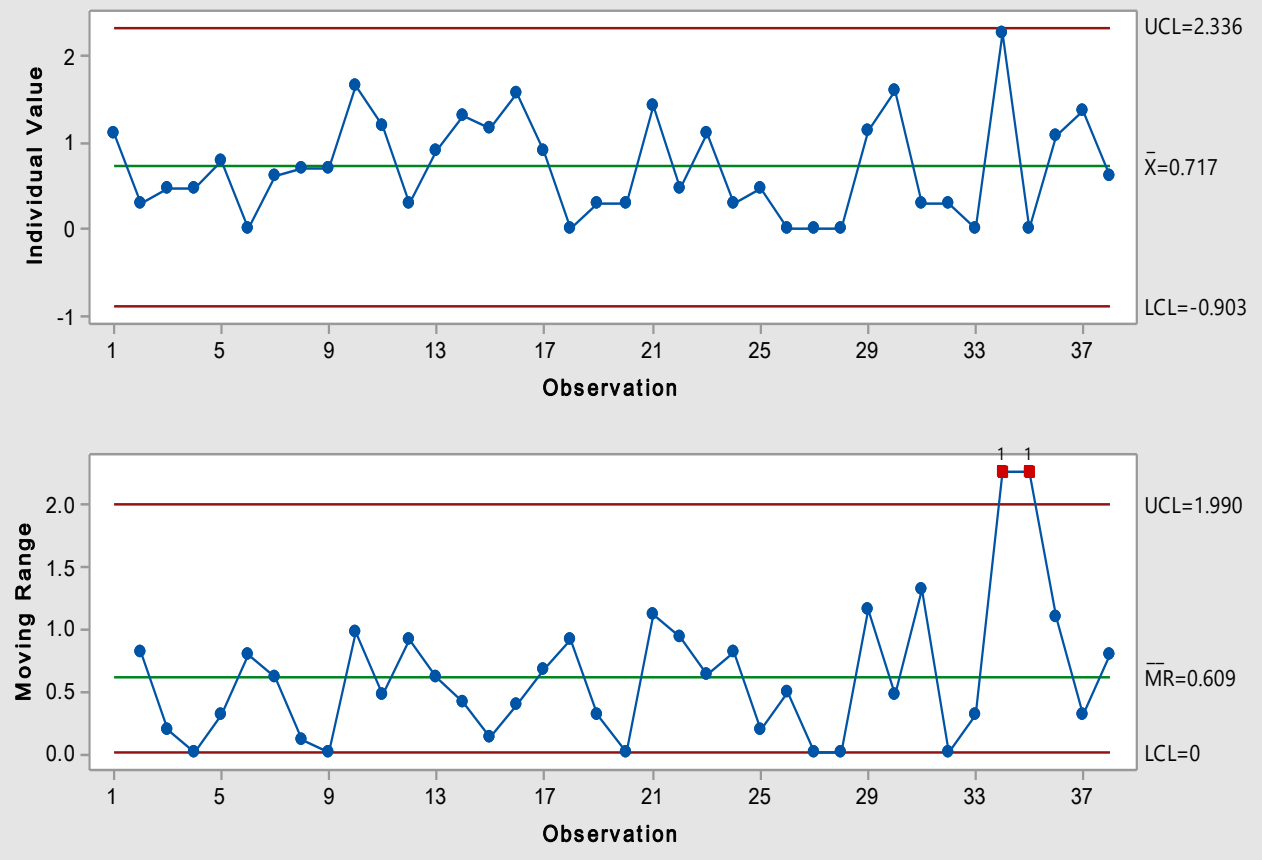

Figure 6. Shewhart Chart of the Restaurant City Water Point for the Employees and Workers Covering a Period of 38 Months of Microbiological Sampling and Testing

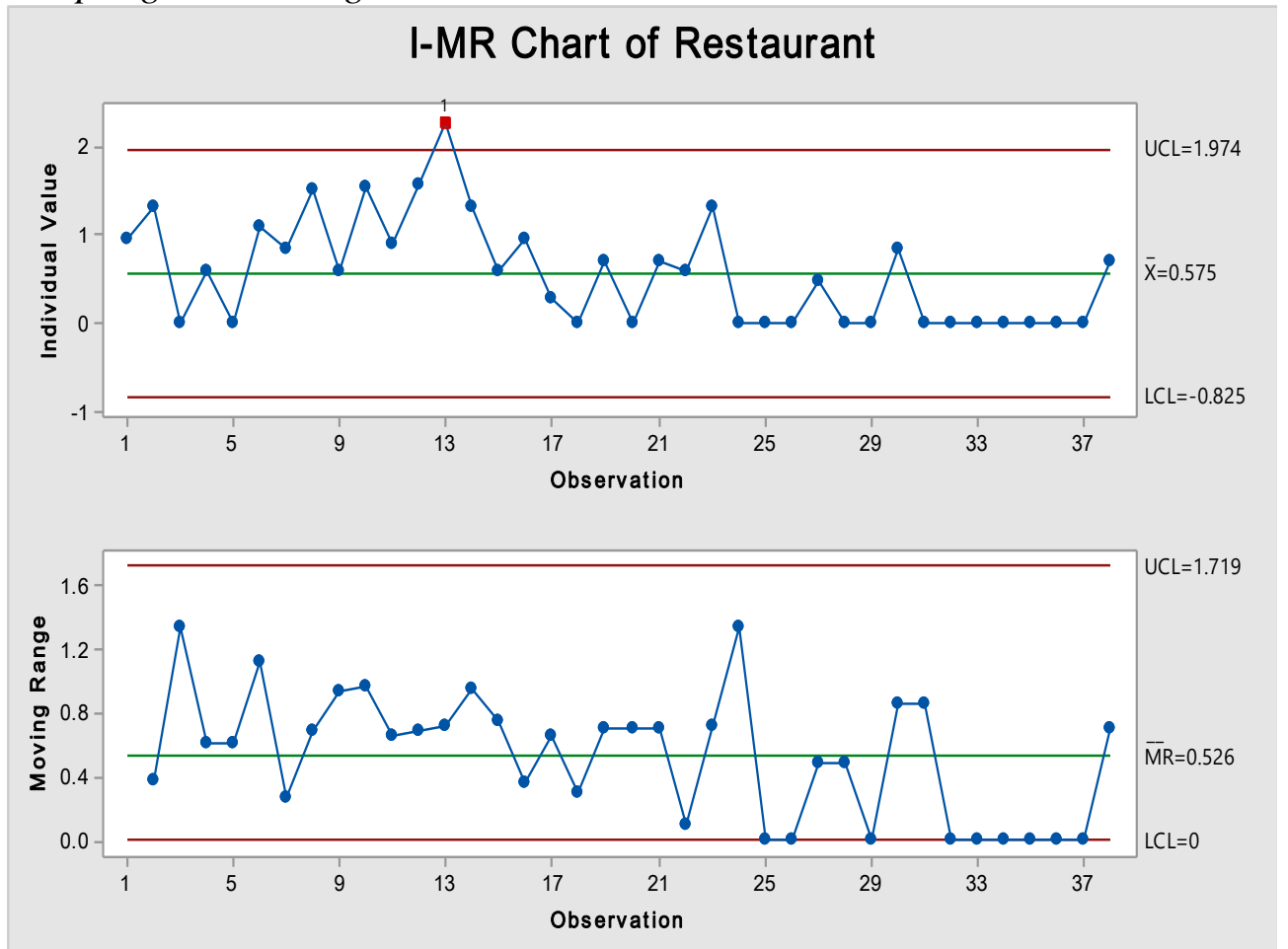


Figure 7. Shewhart Chart of the Production Locker City Water Point Covering a Period of 38 Months of Microbiological Sampling and Testing

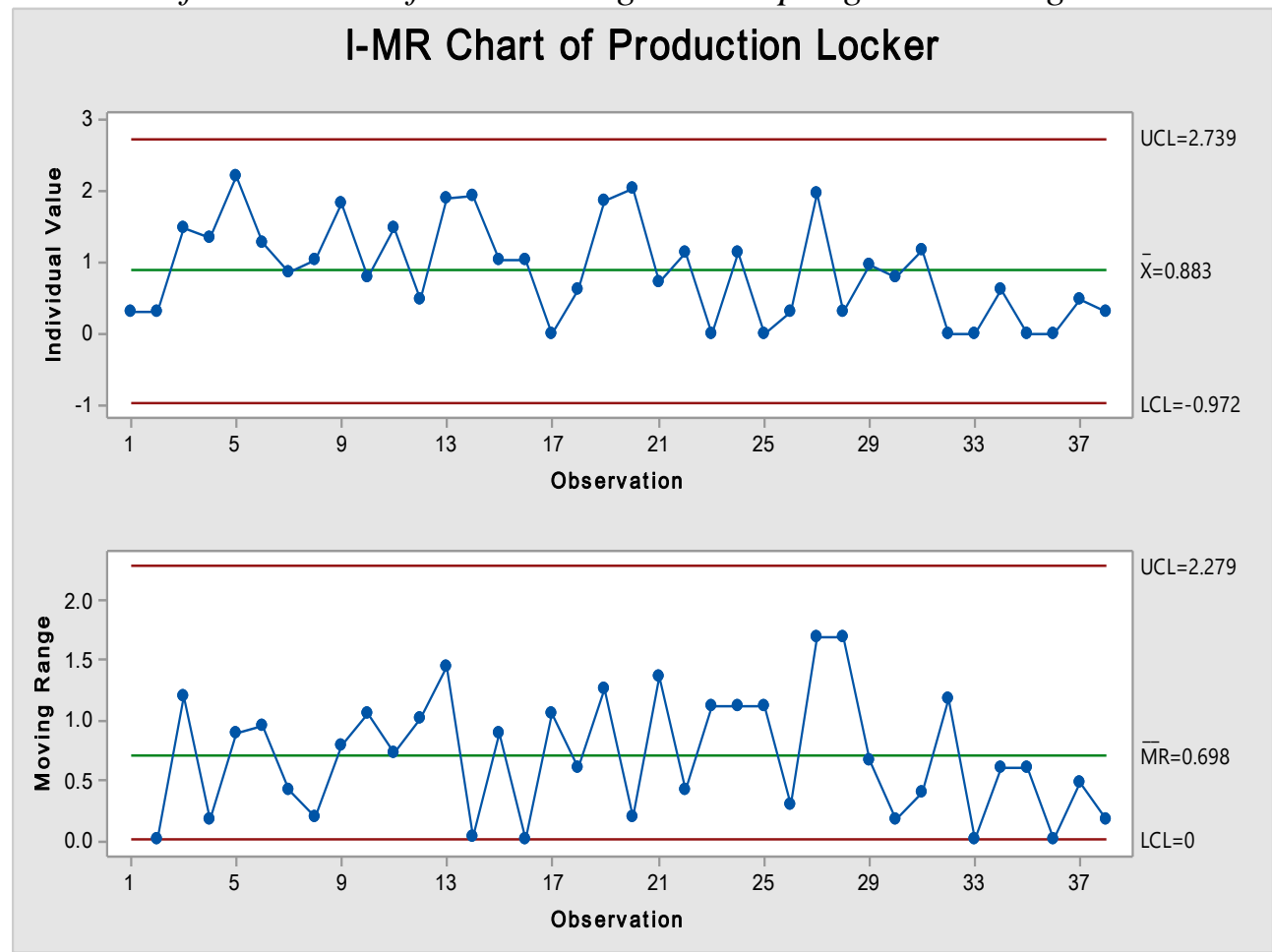

Figure 8. Shewhart Chart of the Laboratory Locker City Water Point Covering a Period of 38 Months of Microbiological Sampling and Testing

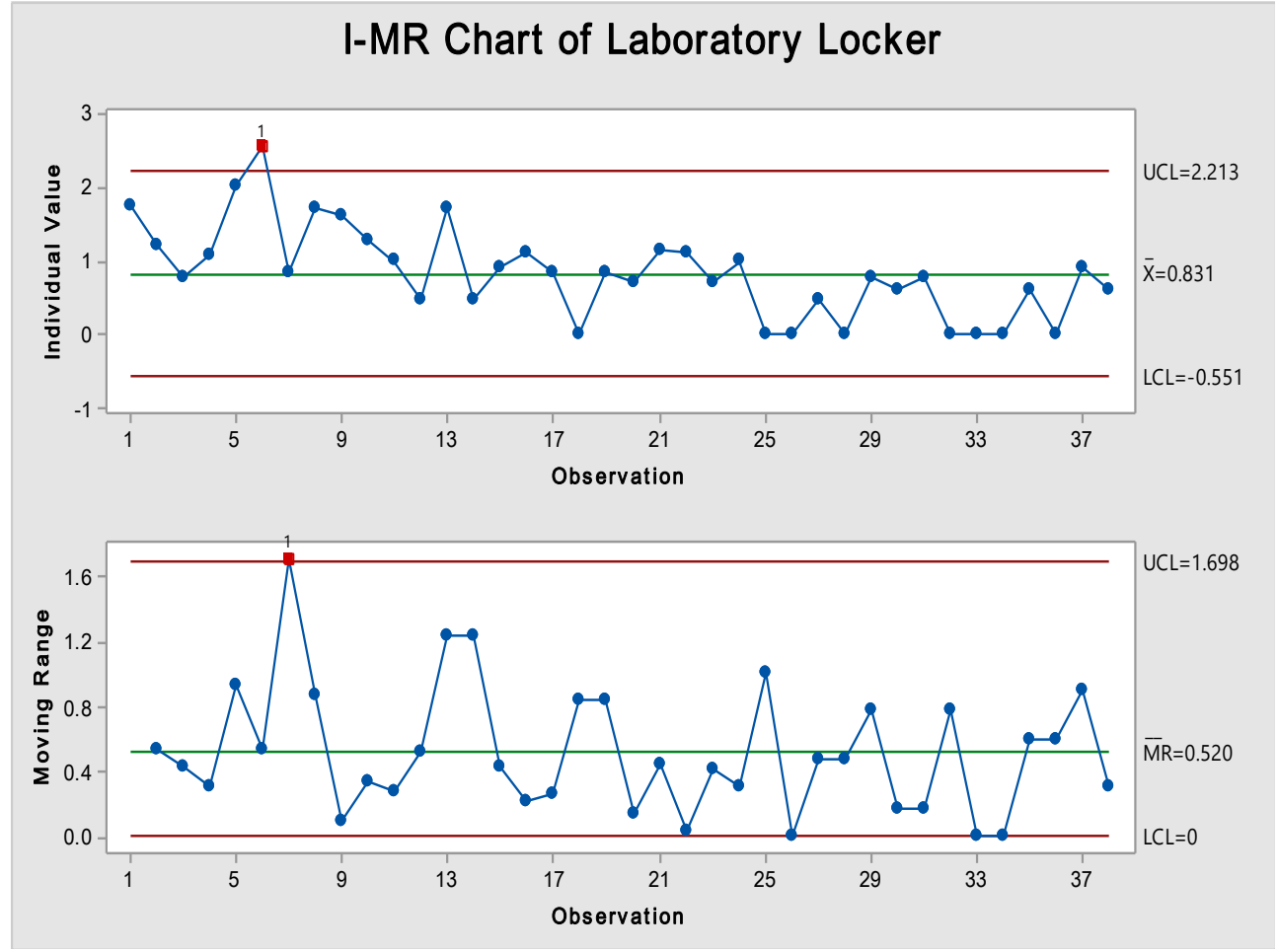


Figure 9. Shewhart Chart of the Average Microbiological Quality of the City Water Distribution System in the Pharmaceutical Plant Covering a Period of 38 Months of Microbiological Sampling and Testing

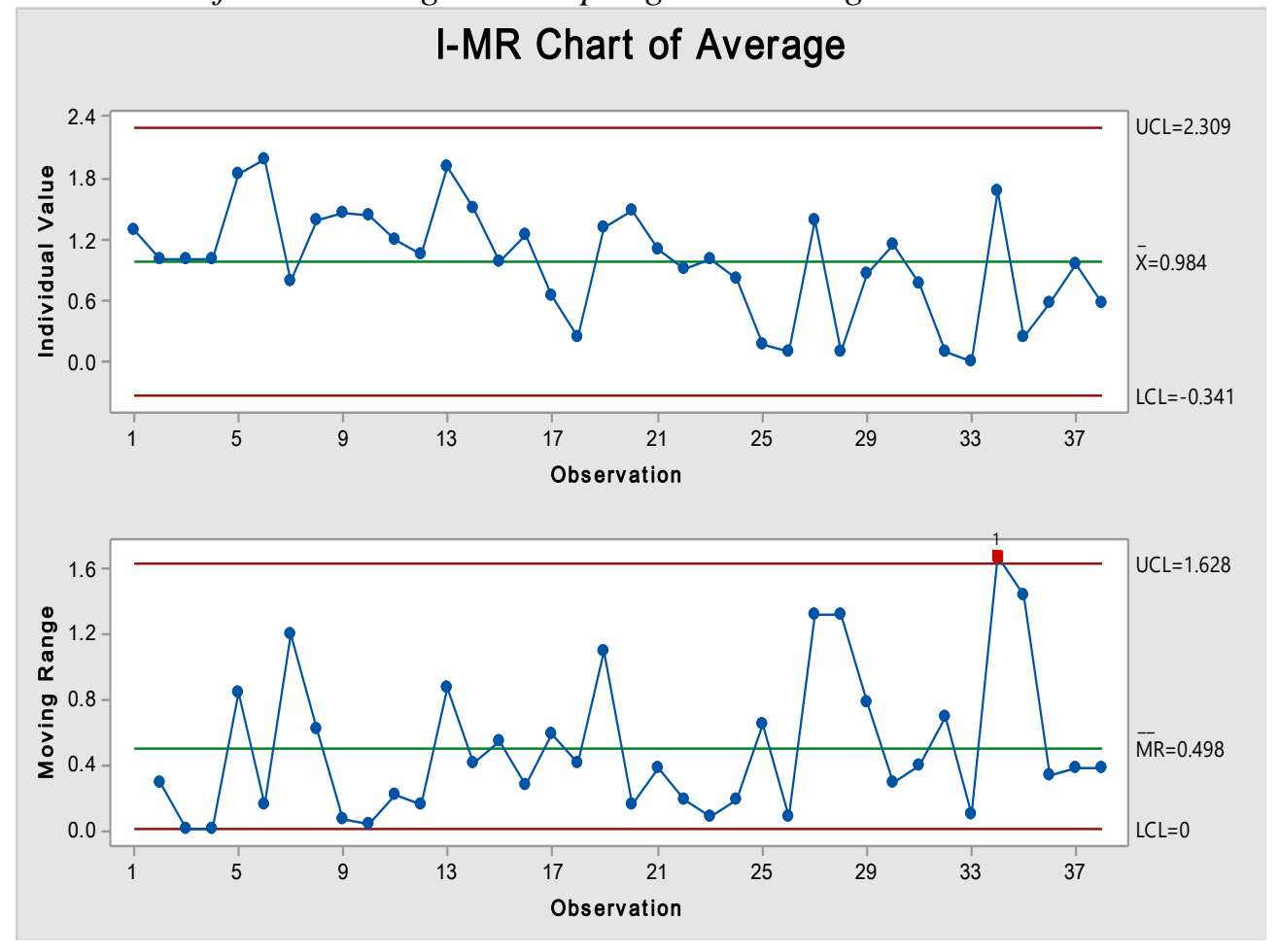

Figure 10. Pareto Diagram Showing the Main City Water Line at the Highest Risk of Microbiological Failure based on the Upper Control Limits (UCL)

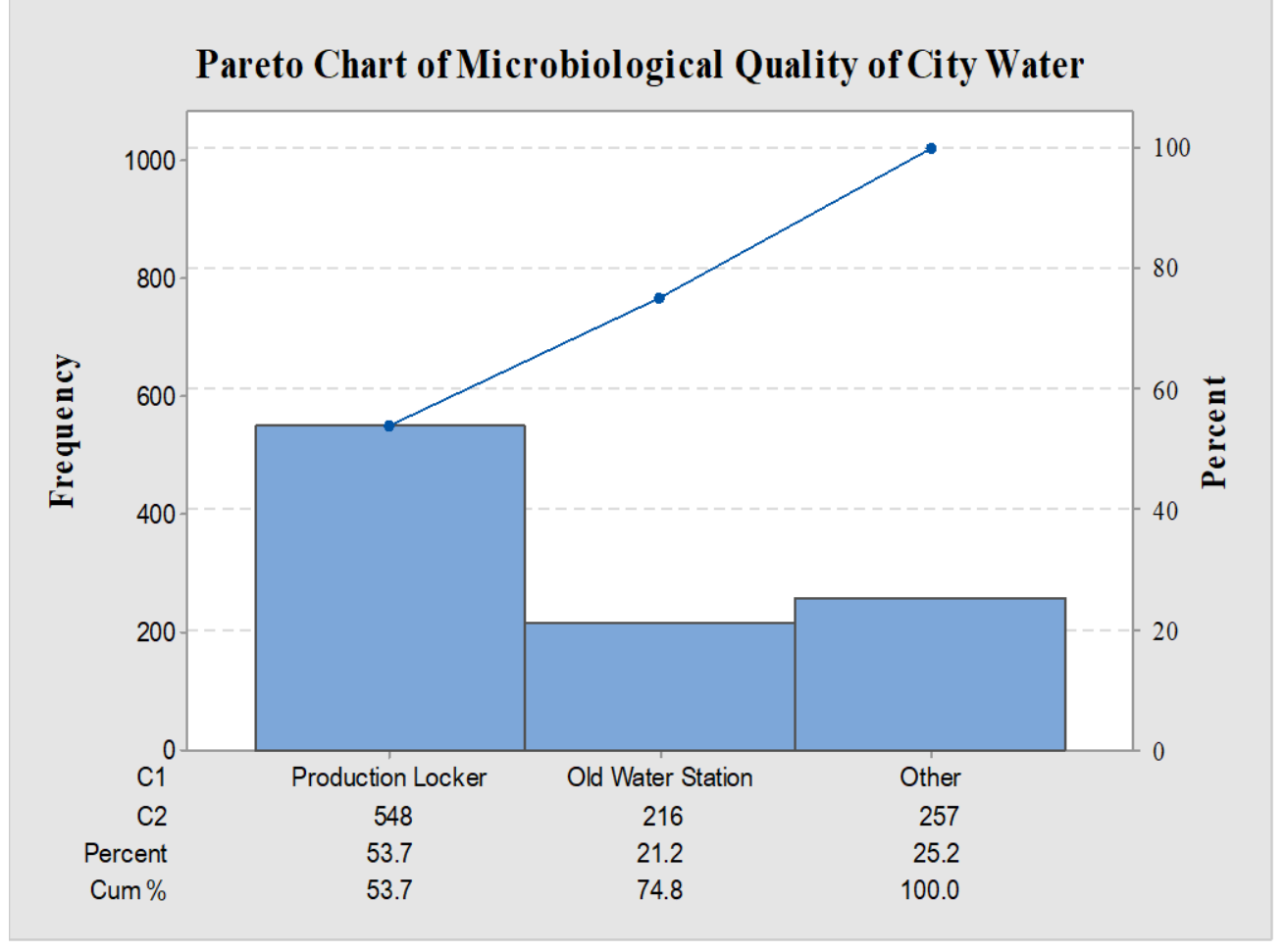


The theory of biological stability and its influence on a system's microbiology has been studied extensively in the structure of non-chlorinated drinking water distribution systems (Hammes et al., 2010a; Van Der Kooij, 2000; Lautenschlager et al., 2013; Rittmann and Snoeyink, 1984; Van der Wielen and Van der Kooij, 2010; Vital et al., 2012). Nevertheless, numerous water processing stations globally deploy a terminal sanitization procedure to ensure destroying viable microbial cells before entering the distribution framework. The sanitization process is frequently accomplished by oxidative cleansing, typically by chlorination (LeChevallier and Au, 2004). Chlorinated water is distributed from the tank to the distribution pipe system to the terminal points-of-use as illustrated in the diagram of Figure 1. Amid chlorination, one can expect that impressive portions of microscopic organisms in the water are inactivated or destroyed, while some lingering chlorine might stay in the water. This could be obvious through various microbial observing techniques. For instance, the quantity of cultivable microorganisms, determined in agar plates, would lessen drastically (Delahaye et al., 2003). Taking after beginning sanitization, leftover chlorine may incite undesirable changes amid drinking water conveyance. When considering all variables that influence the water distribution system, the proximity and availability of nutrient for microbial growth, the presence of low level of competing bioburden and the absence of constant-level supply of disinfectant would increase the risk of biological instability of the distribution water framework. It was obvious from the control charts - in Figure 5-8 - and when excluding extraneous points that the water distribution section of restaurant followed by laboratory locker showed different spots of out-of-control conditions. Other than the significance of supplementing nutrient materials, the degree of bacterial development will be affected by various elements. For instance, expanded water temperature can quicken chlorine decomposition and support microscopic organisms development (Van der Wielen and Van der Kooij, 2010; Jjemba et al., 2010), while changes in hydraulic conditions may modify the nutrient availability to microorganisms in biofilms and/or bacteria separation from the pipe surfaces (Lehtola et al., 2006; Manuel et al., 2007). Moreover, the nature of materials in contact with drinking water, and in addition the vicinity of residue and sediments, can both influence the general microbial nature of the water (Liu et al., 2013; Bucheli-Witschel et al., 2012; Douterelo et al., 2014).

Previous analyses that were done by several researchers showed that when water stream was accelerated, the processes of both bacterial detachment from biofilms and re-suspension of sediments could be induced. Consequently, bacterial cell density would be significantly increased as demonstrated at a research facilities scale. (Lehtola et al., 2006; Manuel et al., 2007; Tsai, 2005). In addition, it is possible that lower water consumption overnight resulted in considerably reduced flow rates, and consequently a faster decay of chlorine and increased bacterial growth (Prévost et al., 1998; Srinivasan et al., 2008).

Although a culture technique for water samples has been described by several guidelines, the observed low recovery of microbes from the conventional plate count agar may not show the full picture of the water quality 
as other techniques (Berney et al., 2008; Siebel et al., 2008). This could be explained in view of the finding of other researchers for the very low recovery of microbes from the commonly used culture methods (Siebel et al., 2008; Hammes et al., 2010b). Moreover, Mezule et al., 2013 demonstrated cases in which bacterial cells from both potable water and biofilms sources - sampled from investigated distribution water systems - were in viable-but-not-cultivable (VNBC) state. Under such circumstances, the microbial particles may be skipped without being detected on/in conventional culture media.

Shewhart control charts showed in general the instability and out-ofcontrol variations in the microbiological quality of city water which may be originated from external and/or intrinsic root-causes. Interestingly, all tested samples have met the acceptance criteria of microbiological testing and quality $\left(\mathrm{P}_{\mathrm{pk}}\right)$. However, the bioburden instability finding revealed by control charts is supported by data demonstrated by Nescerecka et al., 2014, that clearly showed the state of biological instability and variability throughout the distribution system. The researchers demonstrated that in any case, in spite of the relative simplicity of the idea, an intricate interchange of chemical, physical and biological parameters and water driven conditions should be considered in identifying each specific situation of the instability.

\section{Conclusions}

The reliance on conventional microbiological testing of potable water requires review. The need for more sensitive techniques or technologies is required even if proper neutralization of biocidal agents in water - for subsequent culture on agar media - was achieved. Control charts were useful in identifying out-of-control states even if the process met the specification limits. The state of biological instability of the city water distribution system could be spotted using a Statistical process control (SPC) either in a single line or between different segements in the same distribution system. Thus, appropriate maintenance is required to improve microbiological stability of the system and minimize fluctuations in water quality. Accordingly, further investigation is required to elucidate areas of defects in view of different discussed possible factors, either alone or in combination. These contributing parameters can influence the microbiological behavior of each studied segment of the drinking water system and hence its safety for consumption.

\section{Acknowledgments}

This work was supported partially financially by HIKMA Pharma pharmaceutical company - 2nd Industrial zone - 6th of October city. The practical part of all experiments was performed in the microbiology laboratory in the quality control department. Data gathering and issuing was performed by 
the HIKMA microbiology laboratory team. Reference and writing style review was performed by Dr. Engy Refaat Rashed.

\section{References}

Ashour, M. S., Mansy, M. S. and Eissa, M. E., 2011. Microbiological environmental monitoring in pharmaceutical facility. Egypt. Academic J. Biol. Sci, 3(1):63-74.

Bartram, J., Cotruvo, J., Exner, M., Fricker, C. and Glasmacher, A. 2004. Heterotrophic plate count measurement in drinking water safety management. International Journal of Food Microbiology, 92(3): 241-247.

Berardinelli, C. (2016). A Guide to Control Charts. [online] Isixsigma.com. Available at: http://bit.ly/2fxXxxM [Accessed 27 October 2016].

Berney, M., Vital, M., Hülshoff, I., Weilenmann, H., Egli, T. and Hammes, F. 2008. Rapid, cultivation-independent assessment of microbial viability in drinking water. Water Research, 42(14): 4010-4018.

Boe-Hansen, R., Albrechtsen, H., Arvin, E. and Jørgensen, C. 2002. Bulk water phase and biofilm growth in drinking water at low nutrient conditions. Water Research, 36(18): 4477-4486.

Bucheli-Witschel, M., Kötzsch, S., Darr, S., Widler, R. and Egli, T. 2012. A new method to assess the influence of migration from polymeric materials on the biostability of drinking water. Water Research, 46(13): 4246-4260.

Clontz, L. (2008). Microbial Limit and Bioburden Tests. Hoboken: Taylor \& Francis Ltd.

Delahaye, E., Welté, B., Levi, Y., Leblon, G. and Montiel, A. 2003. An ATP-based method for monitoring the microbiological drinking water quality in a distribution network. Water Research, 37(15): 3689-3696.

Douterelo, I., Husband, S. and Boxall, J. 2014. The bacteriological composition of biomass recovered by flushing an operational drinking water distribution system. Water Research, 54: 100-114.

Eissa, M., Seif, M. and Fares, M., 2015. Assessment of purified water quality in pharmaceutical facility using six sigma tools. Int. J. Qual. Assur,6(2): 54-72.

Eissa, M. 2016. Shewhart Control Chart in Microbiological Quality Control of Purified Water and its Use in Quantitative Risk Evaluation. UK Journal of Pharmaceutical Biosciences, 4(1).

Englehardt, J., Swartout, J. and Loewenstine, C. 2009. A new theoretical discrete growth distribution with verification for microbial counts in water. Risk Analysis. 29(6): 841-856.

Fda.gov. Water for Pharmaceutical Use [Internet]. 2016 [cited 1 February 2016]. Available from: http://bit.ly/2fhycF5.

Hammes, F., Berney, M., Wang, Y., Vital, M., Köster, O. and Egli, T., 2008. Flowcytometric total bacterial cell counts as a descriptive microbiological parameter for drinking water treatment processes. Water Research, 42(1): 269-277.

Hammes, F., Berger, C., Köster, O. and Egli, T. 2010a. Assessing biological stability of drinking water without disinfectant residuals in a full-scale water supply system. Journal of Water Supply: Research and Technology-AQUA, 59(1): 31 .

Hammes, F., Goldschmidt, F., Vital, M., Wang, Y. and Egli, T. 2010b. Measurement and interpretation of microbial adenosine tri-phosphate (ATP) in aquatic environments. Water Research, 44(13): 3915-3923. 
Jjemba P, Weinrich L, Cheng W, Giraldo E, LeChevallier MW. Guidance document on the microbiological quality and Biostability of reclaimed water following storage and distribution. WateReuse Research Foundation. 2010.

Juhna, T., Birzniece, D., Larsson, S., Zulenkovs, D., Sharipo, A., Azevedo, N., Menard-Szczebara, F., Castagnet, S., Feliers, C. and Keevil, C. 2007. Detection of Escherichia coli in Biofilms from Pipe Samples and Coupons in Drinking Water Distribution Networks. Applied and Environmental Microbiology, 73(22): 7456-7464.

Lautenschlager, K., Hwang, C., Liu, W., Boon, N., Köster, O., Vrouwenvelder, H., Egli, T. and Hammes, F. 2013. A microbiology-based multi-parametric approach towards assessing biological stability in drinking water distribution networks. Water Research, 47(9): 3015-3025.

LeChevallier, M. and Au, K. 2004. Water treatment and pathogen control. London: IWA Publishing, pp. 136.

LeChevallier, M. W., Welch, N. J. and Smith, D. B., 1996. Full-scale studies of factors related to coliform regrowth in drinking water. Applied and Environmental Microbiology, 62(7): 2201-2211.

Lehtola, M., Laxander, M., Miettinen, I., Hirvonen, A., Vartiainen, T. and Martikainen, P. 2006. The effects of changing water flow velocity on the formation of biofilms and water quality in pilot distribution system consisting of copper or polyethylene pipes. Water Research, 40(11): 2151-2160.

Liu, G., Lut, M., Verberk, J. and Van Dijk, J. 2013. A comparison of additional treatment processes to limit particle accumulation and microbial growth during drinking water distribution. Water Research, 47(8): 2719-2728.

Manuel, C., Nunes, O. and Melo, L. 2007. Dynamics of drinking water biofilm in flow/non-flow conditions. Water Research, 41(3): 551-562.

Mezule, L., Larsson, S. and Juhna, T., 2013. Application of DVC-FISH method in tracking Escherichia coli in drinking water distribution networks .Drinking Water Engineering and Science, 6(1): 25-31.

Nescerecka, A., Rubulis, J., Vital, M., Juhna, T. and Hammes, F., 2014. Biological instability in a chlorinated drinking water distribution network. PloS one, 9(5): e96354.

Niquette, P., Servais, P. and Savoir, R., 2001. Bacterial dynamics in the drinking water distribution system of Brussels. Water research, 35(3): 675-682.

Pharmaguideline.com, (2016). Growth Promotion Test (GPT) for Culture Media. [online] Available at: http://bit.ly/2eCBJw6 [Accessed 11 Feb. 2016].

Polanska, M., Huysman, K. and van Keer, C. 2005. Investigation of assimilable organic carbon (AOC) in flemish drinking water. Water Research, 39(11): 22592266.

Prévost, M., Rompré, A., Coallier, J., Servais, P., Laurent, P., Clément, B. and Lafrance, P. 1998. Suspended bacterial biomass and activity in full-scale drinking water distribution systems: Impact of water treatment. Water Research, 32(5): 1393-1406.

Ramseier, M., Peter, A., Traber, J. and von Gunten, U. 2011. Formation of assimilable organic carbon during oxidation of natural waters with ozone, chlorine dioxide, chlorine, permanganate, and ferrate. Water Research, 45(5): 2002-2010.

Rittmann, B. E., Snoeyink, V. L. 1984. Achieving biologically stable drinking water. Journal of the American Water Works Association, 76(10): 106-14.

Siebel, E., Wang, Y., Egli, T. and Hammes, F. 2008. Correlations between total cell concentration, total adenosine tri-phosphate concentration and heterotrophic plate 
counts during microbial monitoring of drinking water. Drink. Water Eng. Sci. Discuss., 1(1): 71-86.

Srinivasan, S., Harrington, G., Xagoraraki, I. and Goel, R. 2008. Factors affecting bulk to total bacteria ratio in drinking water distribution systems. Water Research, 42(13): 3393-3404.

Support.minitab.com. (2016). Ppk, PPU, PPL, and Cpm: Measures of overall process capability - Minitab. [online] Available at: http://bit.ly/2fhto2s [Accessed 30 Oct. 2016].

Tsai, Y. 2005. Impact of flow velocity on the dynamic behaviour of biofilm bacteria. Biofouling, 21(5-6): 267-277.

Van der Kooij, D., 1990. Assimilable organic carbon (AOC) in drinking water. In Drinking water microbiology (pp. 57-87). Springer New York.

Van Der Kooij, D., 2000. Biological stability: a multidimensional quality aspect of treated water. Water, air, and soil pollution, 123(1-4): 25-34.

Van der Wielen, P. W. and Van der Kooij, D., 2010. Effect of water composition, distance and season on the adenosine triphosphate concentration in unchlorinated drinking water in the Netherlands. Water Research, 44(17): 4860-4867.

Vincent, D. W., 2003. Qualification of purified water systems. Journal of validation technology, 10(1): 50-61.

Vital, M., Hammes, F. and Egli, T. 2008. Escherichia coli O157 can grow in natural freshwater at low carbon concentrations. Environmental Microbiology, 10(9): 2387-2396.

Vital, M., Stucki, D., Egli, T. and Hammes, F. 2010. Evaluating the Growth Potential of Pathogenic Bacteria in Water. Applied and Environmental Microbiology, 76(19): 6477-6484.

Vital, M., Dignum, M., Magic-Knezev, A., Ross, P., Rietveld, L. and Hammes, F. 2012. Flow cytometry and adenosine tri-phosphate analysis: Alternative possibilities to evaluate major bacteriological changes in drinking water treatment and distribution systems. Water Research, 46(15): 4665-4676.

Weinrich, L., Jjemba, P., Giraldo, E. and LeChevallier, M. 2010. Implications of organic carbon in the deterioration of water quality in reclaimed water distribution systems. Water Research, 44(18): 5367-5375.

WHO Guidelines for Drinking-Water Quality, $3^{\text {rd }}$ edition. Geneva, World Health Organization, 2003. 